\title{
Prevalence of dehiscences and fenestrations in human cadavers
}

\author{
Ewaldo Antônio Vieira Rodrigues, ${ }^{1}$ Walter Augusto Soares Machado, ${ }^{2}$ Casimiro Abreu Possante de Almeida, ${ }^{3}$ Andréia Cristina Breda de Souza, ${ }^{3}$ Cláudia \\ Callegaro de Menezes, ${ }^{1}$ Marcos de Oliveira Barceleiro, ${ }^{4}$ Walmir Júnio de Pinho Reis Rodrigues, ${ }^{5}$ Mario Taba Jr, ${ }^{6}$ Sérgio Kahn ${ }^{1}$ \\ ${ }^{1}$ Master of Science Program in Oral Rehabilitation, Veiga de Almeida University, Rio de Janeiro, RJ, Brazil \\ ${ }^{2}$ Department of Periodontology, Veiga de Almeida University, Rio de Janeiro, Rio de Janeiro, RJ, Brazil \\ ${ }^{3}$ Department of Forensic Dentistry, Federal University of Rio de Janeiro, Rio de Janeiro, RJ, Brazil \\ ${ }^{4}$ Department of Restorative Dentistry, Fluminense Federal University, Nova Friburgo, RJ, Brazil \\ ${ }^{5}$ Dentistry Graduation, Serra dos Órgãos University Center - UNIFESO, Teresópolis, RJ, Brazil \\ ${ }^{6}$ Department of Oral \& Maxillofacial Surgery and Periodontology, University of São Paulo, Ribeirão Preto, SP, Brazil \\ - Conflicts of interest: none declared.
}

Abstract

Objective: the aim of the present study was to evaluate the prevalence of dehiscences and fenestrations in a convenience sample of human cadavers to provide accurate identification of bone defects. Material and Methods: twenty human cadavers, ranging in age from 20 to 40 years, were evaluated for dehiscences and fenestrations, which were verified after mucoperiosteal flap elevation. Results: the prevalence of dehiscences and fenestrations in the specimens was confirmed as being $40 \%$, accounting for $5 \%$ of teeth with lesions. The most prevalent lesions were dehiscences, while only one single case of maxillary fenestration was observed. Conclusion: the planning of any periodontal plastic surgeries performed in the anterior region must take into account the possibility of periodontal defects. Therefore, considering the high prevalence of bone defects with potential impact in the esthetic outcome, the manipulation of soft tissues should be done carefully, especially in patients with a thin periodontium.

Keywords: Periodontium; Jaw/anatomy and histology; Dehiscences; Cadaver.

\section{Introduction}

ש enestrations and dehiscences are two types of alveolar bone defects that occur frequently in a large part of the population. ${ }^{1,2}$ Fenestrations are described as lesions in which the vestibular or lingual bone plate is absent from the surface of roots, without affecting the marginal bone tissue. Defects in which the marginal bone tissue is also absent are called dehiscences. These defects have been reported to be more common on the anterior teeth. ${ }^{3}$

Davies et al..$^{4}$ first defined dehiscences in numerical terms, establishing that the alveolar bone crest is apically placed to the extent of at least $4 \mathrm{~mm}$ in relation to the interproximal bone crest.

These two types of lesions may be obstacles for surgical procedures, especially in periodontal plastic surgeries. ${ }^{1,2,5,7}$ Therefore, it is important for professionals to understand the clinical characteristics, incidence, prevalence and distribution of these lesions during the planning and performance of mucogingival surgeries.

Various authors ${ }^{8-11}$ have described different classifications of periodontal morphotypes, proposing an association between the width of attached gingiva, gingival thickness and bone thickness.

Different periodontal morphotypes may be related to more or less favorable treatment outcome and the healing process may behave distinctly even after identical clinical procedure such as similar trauma or surgical manipulation.
Thin periodontium in patients with periodontitis normally develop gingival recession, whereas thicker periodontium tends to present fibrosis, edema and periodontal pockets. ${ }^{11}$ Periodontal surgeries to promote root coverage in thinner tissues appear to be less predictable ${ }^{12-13}$ and their surgical manipulation is more difficult. ${ }^{14}$

As it may be observed, despite the different criteria for classifying the periodontal morphotype, groups that present a large gingival width also present thick gingiva and bone. Similarly, groups that present a reduced gingival width also present thinner gingiva and bone. Therefore, dehiscences and fenestrations have been shown to be more common in patients with a thin periodontal morphotype. ${ }^{11}$

The etiologic factors associated with fenestrations and dehiscences have not been fully explained, although some factors have been discussed in the literature. Among these factors are: the size and position of the teeth, ${ }^{1,2,5,715}$ alveolar bone thickness, ${ }^{5,7,15-17}$ frenum insertions, developmental anomalies, ${ }^{1,2}$ extractions, ${ }^{3}$ teeth that have undergone orthodontic movement, ${ }^{2}$ patient's age, periodontal and endodontic lesions $\mathrm{s}^{4,2}$ and occlusal trauma. ${ }^{2,15}$

Malpositioned teeth, and other anatomic situations such as high frenum insertions and shallow vestibules, if associated with fenestration and dehiscence lesions, may lead to gingival recession. ${ }^{18}$ Additionally, orthodontic movement of teeth with prominent roots and thin alveolar bone also require special care to prevent the appearance of these defects. ${ }^{2}$ 
These bone alterations in the buccal aspect of the alveolar bone are usually difficult to be clinically detected unless the gingival tissue shows some evidence by tissue transparency or recession. Additionally, conventional radiographs are also very limited to provide detailed information on the buccal aspect of the teeth, due mainly to superposition of anatomic structures.

Some methods have been used to evaluate the prevalence and distribution of dehiscences and fenestrations, among which analysis of dry skulls, ${ }^{1,2,4,5,15,19}$ and cone beam computerized tomography. ${ }^{20-22}$ The aim of the present study was to assess dehiscences and fenestrations in human cadavers.

\section{Study Population}

\section{Material and Methods}

Twenty human cadavers, whose death occurred less than 48 hours prior to evaluation and age ranging from 20 to 40 years, irrespective of sex, were included in this study. The cadavers were selected at the Forensic Medicine Institute Afrânio Peixoto in Rio de Janeiro-RJ, Brazil, after authorization from the Institute's board of directors. Ethical approval was obtained by the Research Ethics Committees of Veiga de Almeida University (Protocol Number 131/08) and of the Institute (Protocol Number 002/2008).

\section{Evaluation of Defects}

Presence or absence of dehiscences and fenestrations was evaluated in canines, lateral incisors and central incisors, totalizing 240 teeth, 120 maxillary and 120 mandibular. To enable the visualization of these defects, a full thickness flap elevation was performed, extending between the first premolars in both arches (Figures 1 and 2). To evaluate the presence or absence of dehiscences and fenestrations, a clinical exam was performed (Figure 3) and photographs were taken with a digital camera. To detect dehiscences (Figure 4) and fenestrations, two previously calibrated examiners performed the evaluation. In the event of a divergence between the examiners, a third, experienced professional evaluated the case for settling the divergence. Upon conclusion of the clinical exams and analysis of the photographs, the flaps were repositioned in accordance with the Institute's directions for restoration and closure of cadavers.

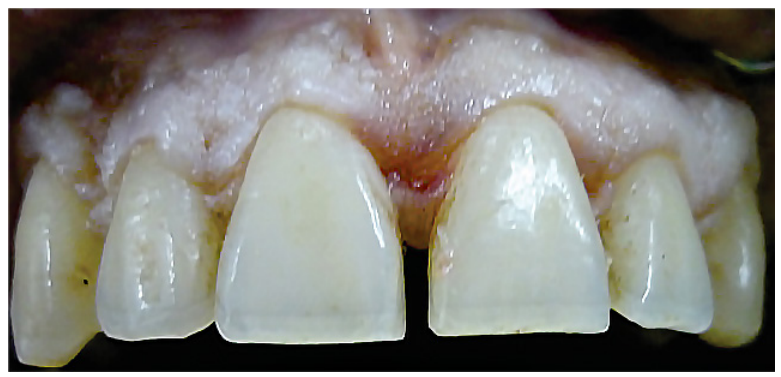

Figure 1. Initial incision before maxillary flap elevation

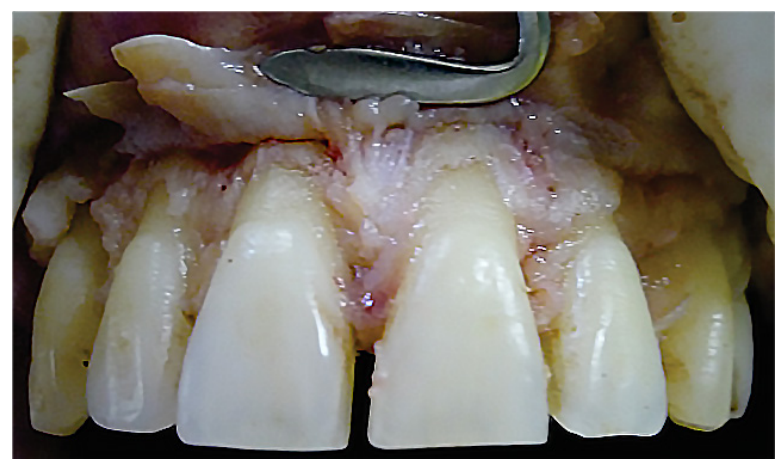

Figure 2. Maxillary flap elevation

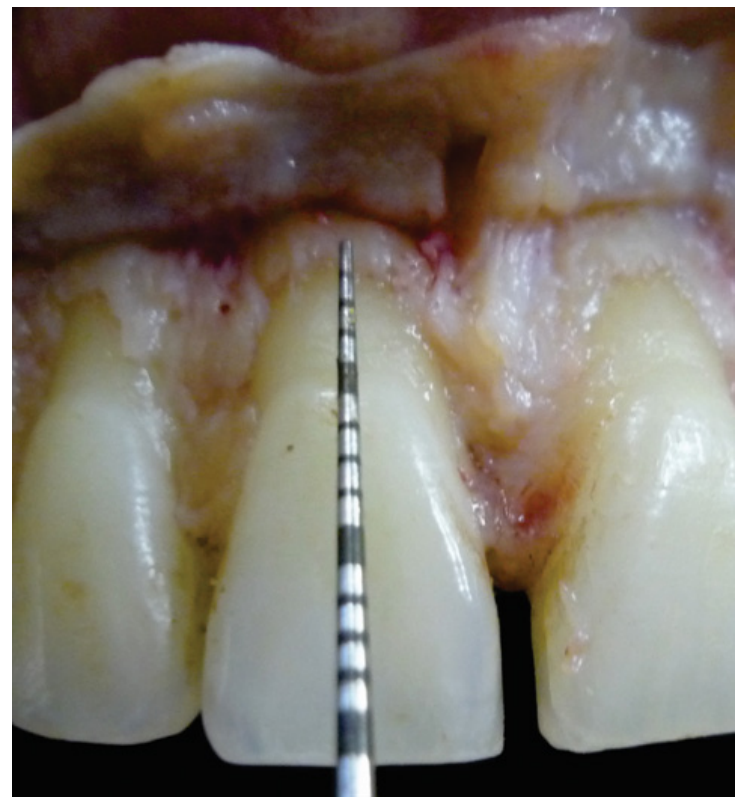

Figure 3. Clinical examination of maxillary teeth

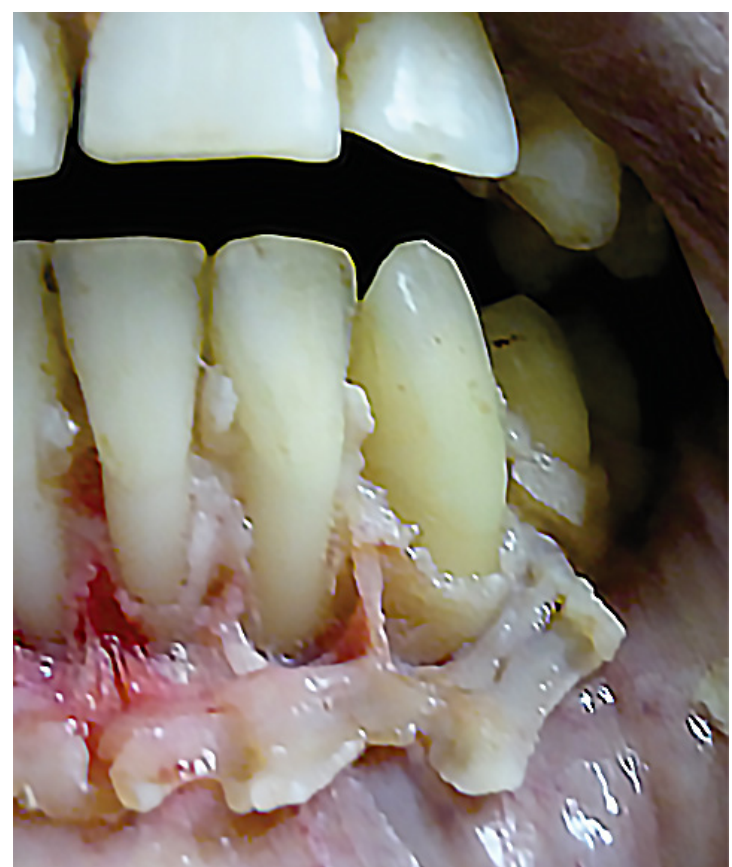

Figure 4. Example of dehiscence involving a mandibular left lateral incisor 


\section{Results}

After data analysis, the results obtained (Table 1) demonstrated that $17(85.00 \%)$ specimens were male and $3(15.00 \%)$ were female. The mean age was 25.6 years, with a maximum age of 38 and minimum of 18 years. With regards to skin color, 15 (75.00\%) specimens were black and 5 (25.00\%) were white.

Table 1. Frequencies of specimens according to sex skin color, presence of dehiscences and fenestrations among specimens according to the site and teeth

\begin{tabular}{lc|c|c}
\hline \multicolumn{1}{c|}{ Sex } & Number & $(\%)$ \\
\hline Male & 17 & $(85.00)$ \\
\hline Female & 3 & $(15.00)$ \\
\hline
\end{tabular}

\section{Skin color}

\begin{tabular}{|l|c|c|}
\hline Black & 15 & $(75.00)$ \\
\hline White & 5 & $(25.00)$ \\
\hline
\end{tabular}

Frequency of defects among specimens

\begin{tabular}{l|c|c}
\hline Present & 8 & $(40.00)$ \\
\hline Absent & 12 & $(60.00)$ \\
\hline
\end{tabular}

\section{Frequency of defects in relation}

to teeth

\begin{tabular}{l|c|c}
\hline Present & 12 & $(5.00)$ \\
\hline Absent & 228 & $(95.00)$ \\
\hline
\end{tabular}

\section{Presence of maxillary}

dehiscences among specimens

\begin{tabular}{l|c|c}
\hline Present & 5 & $(25.00)$ \\
\hline Absent & 15 & $(75.00)$ \\
\hline
\end{tabular}

Presence of mandibular

dehiscences among specimens

\begin{tabular}{l|c|c}
\hline Present & 4 & $(20.00)$ \\
\hline Absent & 16 & $(80.00)$ \\
\hline
\end{tabular}

Presence of maxillary fenestra-

tions among specimens

\begin{tabular}{l|c|c}
\hline Present & 1 & $(5.00)$ \\
\hline Absent & 19 & $(95.00)$ \\
\hline
\end{tabular}

Presence of mandibular

fenestrations among specimens

\begin{tabular}{l|c|c}
\hline Present & 0 & $(0)$ \\
\hline Absent & 20 & $(100)$ \\
\hline
\end{tabular}

Evaluation of dehiscences in the maxillary sites revealed that $6(5 \%)$ teeth, belonging to 5 specimens $(25 \%)$ presented this defect: both maxillary central incisors (2 occurrences each) and both maxillary canines (1 occurrence each). Evaluation of dehiscences in the mandibular sites showed that this defect was present in $5(4.16 \%)$ teeth belonging to 4 (20\%) specimens: both mandibular central incisors (2 occurrences each) and the maxillary left canine (1 occurrence).

Only one fenestration was observed in the maxillary lateral incisor in one specimen of the studied sample.
In the entire sample, $8(40 \%)$ specimens presented some type of defect. Dental analysis showed defect in 11 (5\%) teeth.

\section{Discussion}

Periodontal plastic surgery is currently at a stage where there is a great demand for safer and more predictable procedures. Thin periodontium is recognized an obstacle for successful surgical procedures. ${ }^{12-14}$ Therefore, knowing the anatomy of periodontal structures and the characteristics of their variations is mandatory to perform successful surgical therapy. Many authors have drawn attention to the fact that dehiscences and fenestrations could compromise the success of periodontal surgical procedures. ${ }^{1,6,7}$

The distribution of these defects has been evaluated in several studies. Some studies have observed a greater presence of mandibular dehiscences, including Abdelmalek and Bissada, ${ }^{1}$ who found $21.5 \%$ of mandibles and $8.19 \%$ of maxillas with this defect; Edel, ${ }^{15}$ with $5.5 \%$ of mandibles and $2.1 \%$ of maxillas; and Jorgić-Srdjak et al. ${ }^{19}$ who showed the presence of dehiscences in $41.02 \%$ of mandibles versus $26.67 \%$ in maxillas. A similar report was made by Nimigean et al. ${ }^{20}$ who observed the presence of dehiscences in $71.61 \%$ of the evaluated mandibles. In the present study, there was no significant difference in the distribution of dehiscences between the maxilla and mandible. It is important to mention that age was not matched in those different prevalence studies and therefore comparisons must be made carefully.

Studies have shown the most frequent presence of fenestrations in the maxillary bone. Among these reports are those of Abdelmalek and Bissada, ${ }^{1}$ in which maxillary fenestrations were observed in $42.62 \%$ of the specimens evaluated versus $24.73 \%$ of mandibles, and Edel,${ }^{15}$ with $17.70 \%$ of the maxillas presenting the condition versus $5.40 \%$ of mandibles. These results agree with those of the study by Nimigean et al. ${ }^{20}$ in which $74.67 \%$ of the fenestrations were found in the maxillary bone. However, these rates were not reproduced in a study by Jorgić-Srdjak et al., ${ }^{19}$ in which $9.23 \%$ of the maxillas and $9.41 \%$ of mandibles presented fenestrations. Fenestration in the current study was limited to one maxillary case only.

When these defects were evaluated according to the associated teeth, variations occurred in the literature. Larato ${ }^{5}$ observed the presence of these defects in $7.50 \%$ of the evaluated teeth. Abdelmalek and Bissada ${ }^{1}$ obtained similar results, with $6.30 \%$ of the teeth presenting some type of defect. Ghassemian et al. ${ }^{22}$ observed that 3.00 to $7.50 \%$ of the maxillary anterior teeth presented fenestrations and that dehiscences were found in 3.00 to $6.10 \%$ of these teeth. With a rate above those mentioned previously, it is possible to point out studies by Edel, ${ }^{15}$ who obtained a rate of $14.50 \%$, Rupprecht et al. ${ }^{2}$ with $13.00 \%$, Nimigean ${ }^{20}$ with $12.80 \%$ and 
Braut et al., ${ }^{21}$ who observed dehiscences in $25.70 \%$ and fenestrations in $10.00 \%$ of the evaluated teeth. In the present study, fewer defects were observed in the evaluated teeth, accounting to approximately $5.00 \%$ of the cadavers.

Various studies ${ }^{2,15,19,20}$ have demonstrated that the maxillary first molar was the tooth most affected by fenestrations, and that the mandibular canine presented the largest number of dehiscences. The present study evaluated exclusively canines and incisors. The results demonstrated that the maxillary and mandibular central incisors were the most affected teeth by dehiscences, and only one fenestration was observed in a maxillary lateral incisor.

Lindhe $^{3}$ and Larato ${ }^{5}$ demonstrated that these two defects are more common in anterior teeth and their occurrence is related to the removal of some tooth. Katranji et al. ${ }^{17}$ indicated that an increased bone thickness was found in the maxillary region from the premolars to the anterior teeth, which not occurred in the posterior region. The above-mentioned studies have suggested that the presence of a thick cortical bone may be a determining factor for the absence of these lesions, which is supported by Rupprecht et al. ${ }^{2}$

Despite these studies, difficulty in predicting the location and distribution of bone dehiscences and fenestrations has been reported. ${ }^{19}$ Considering this and the fact that a patient may present different types of gingival tissue, a clinician should be able to determine the presence of these defects.

The difference found among the results in the literature may be explained by the use of different methods, different age ranges, specific population behavior and also disease prevalence. Various studies used dry skulls to detected dehiscences and fenestrations, but the present study used human cadavers, in which death had occurred less than 48 hours before, without any risk of post-mortem damage to the anatomic structures of interest and focus of this investigation.

Within the limits of this study, the teeth most affected by dehiscences and fenestrations were the central incisors and canines. There was a predisposition of defects among males, but the larger number of male specimens must be taken into account. The prevalence of dehiscences or fenestrations indicated that $40 \%$ of the specimens and $50 \%$ of the teeth presented one of the to evaluated defects, with greater frequency of dehiscences.

Considering the relevant differences in the population, a case-by-case diagnostic evaluation is essential to identify the bone defects. In addition, according to the relative high prevalence of the observed bone alterations and particularly due to the difficulty to identify without a surgical flap elevation, the authors foresee the use of new technologies such as high-definition tridimensional diagnosis as powerful tools to help clinicians choose the best surgical approach.

\section{Conclusion}

It may be concluded that the planning of periodontal plastic surgeries performed in the anterior region must anticipate the presence of periodontal defects. The manipulation of soft tissues should be done carefully, especially in patients with a thin periodontium.

\section{Acknowledgments}

The authors would like to thank Fundação de Amparo à Pesquisa do Estado do Rio de Janeiro for the financial support provided for this work by means of Project Number E-26/110.214/2009.

\section{References}

1. Abdelmalek RG, Bissada N. Incidence and distribution of alveolar bony dehiscence and fenestration in dry human Egyptian jaws. J Periodontol. 1973;44(9):586-8.

2. Rupprecht RD, Horning GM, Nicoll BK, Cohen ME. Prevalence of dehiscences and fenestrations in modern American skulls. J Periodontol. 2001;72(6):722-9.

3. Lindhe J. Clinical periodontology and implant dentistry. 4th ed. Copenhagen: Blackwell Munksgaard; 2003.

4. Davies RM, Downer MC, Hull PS, Lennon MA. Alveolar defects in human skulls. J Clin Periodontol. 1974;1(2):107-11.

5. Larato DC. Alveolar plate fenestrations and dehiscences of the human skull. Oral Surg Oral Med Oral Pathol .1970;29(6):816-9.

6. Lost C. Depth of alveolar bone dehiscences in relation to gingival recessions. J Clin Periodontol. 1984;11(9):583-9.

7. Carranza FA, Newman MG. Clinical Periodontology. 8th ed. Philadelphia: Saunders, 1996.

8. Maynard JG, Wilson RD. Physiologic dimensions of the periodontum significant to the restorative dentist. J Periodontol. 1979;50(4):170-4.

9.Müller HP, Eger T. Gingival phenotypes in young male adults. J Clin Periodontol. 1997;24(1):65-71.

10. Müller HP, Heinecke A, Schaller N, Eger T. Masticatory mucosa in subjects with different periodontal phenotypes. J Clin Periodontol. 2000;27:(9)621-6.

11. Kao RT, Pasquinelli K. Thick VS. Thin gingival tissue: a key determinant in tissue response to disease and restorative treatment. J Calif Dent Assoc.
2002;30(7):521-6.

12. Harris RJ. A comparative study of root coverage obtained with guided tissue regeneration utilizing a bioabsorbable membrane versus the connective tissue with partial-thickness double pedicle graft. J Periodontol. 1997;68(8):779-90.

13. Baldi C, Pini-Prato G, Pagliaro U, Nieri M, Saletta D, Muzzi L, et al. Coronally advanced flap procedure for root coverage. Is flap thickness a relevant predictor to achieve root coverage? A 19-case series. J Periodontol. 1999;70:(9)1077-84.

14. de Campos GV, Bittencourt S, Sallum AW, Nociti Jr FH, Sallum EA, Casati $\mathrm{MZ}$. Achieving primary closure and enhancing aesthetics with periodontal microsurgery. Pract Proced Aesthet Dent. 2006;18(7):449-54.

15. Edel A. Alveolar bone fenestrations and dehiscences in dry Bedouin jaws. J Clin Periodontol. 1981;8(6):491-9.

16. Borghetti A, Monnet-Corti V. Chirurgie plastique parodontale. 2nd ed. Paris: France; 2002.

17. Katranji A, Misch K, Wang HL. Cortical bone thickness in dentate and edentulous human cadavers. J Periodontol. 2007;78(5):874-8.

18. Rufenacht CR. Fundamentals of esthetics. Chicago: Quintessence, 1990.

19. Jorgić-Srdjak K, Plancak D, Bosnjak A, Azinović Z. Incidence and distribution of dehiscences and fenestrations on human skulls. Coll Antropol. 1998;22:111-6. 20. Nimigean VR, Nimigean V, Bencze MA, Dimcevici-Poesina N, Cergan R, Moraru S. Alveolar bone dehiscences and fenestrations: an anatomical study and review. Rom J Morphol Embryol. 2009;50(3):391-7.

21. Braut V, Bornstein MM, Belser U, Buser D. Thickness of the anterior maxil- 
lary facial bone wall-a retrospective radiographic study using cone beam computed tomography. Int J Periodontics Restorative Dent. 2011;31(2):125-31.

22. Ghassemian M, Nowzari H, Lajolo C, Verdugo F, Pirronti T, D’Addona A.
The thickness of facial alveolar bone overlying healthy maxillary anterior teeth. J Periodontol. 2012;83(2):187-97.

\section{Mini Curriculum and Author's Contribution}

1. Ewaldo Antônio Vieira Rodrigues - DDS and MS. Contribution: cadavers selection and evaluation.

2. Walter Augusto Soares Machado - DDS and MS. Contribution: cadavers selection and evaluation.

3. Casimiro Abreu Possante de Almeida - DDS and PhD. Contribution: cadavers selection and evaluation.

4. Andréia Cristina Breda de Souza - DDS and PhD. Contribution: cadavers selection and evaluation.

5. Cláudia Callegaro de Menezes - DDS and MS. Contribution: cadavers selection and evaluation.

6. Marcos de Oliveira Barceleiro - DDS and PhD. Contribution: data analysis and manuscript review.

7. Walmir Júnio de Pinho Reis Rodrigues - DDS and MS. Contribution: data analysis and manuscript writing.

8. Mario Taba Jr - DDS and PhD. Contribution: data analysis and manuscript review.

9. Sérgio Kahn - DDS and PhD. Contribution: cadavers selection and evaluation and manuscript writing.

Submitted: 07/18/2017 / Accepted for publication: 08/04/2017

\section{Corresponding Author}

Sérgio Kahn

E-mail: sergiokahn@terra.com.br 